\title{
Mechanism of DNA repair gene ERCC1 affecting breast cancer metastasis through NF-KB signaling pathways
}

\section{Xiabin Li}

the First Affiliated Hospital of Southwest Medical University

\section{Yongxin Yang}

Guizhou Qiannan People's Hospital

\section{Bin Wu}

First Affiliated Hospital of Southwest Medical University

\section{Haishan Zheng}

First Affiliated Hospital of Southwest Medical University

\section{Liyue Hao}

Southwest Medical University

\section{Tianxiong Wang}

Southwest Medical University

\section{Zhonghua Tao}

Southwest Medical University

Yan Tang ( $\square$ tangyan200310@163.com )

Southwest Medical University

\section{Research Article}

Keywords: ERCC1, Breast Cancer, metastasis, NF-KB signaling pathways

Posted Date: March 7th, 2022

DOI: https://doi.org/10.21203/rs.3.rs-1383097/v1

License: (c) (1) This work is licensed under a Creative Commons Attribution 4.0 International License. Read Full License 
Title:Mechanism of DNA repair gene ERCC1 affecting breast cancer metastasis through NF- $\kappa$ B signaling pathways

Authors:Xiabin $\mathrm{Li}^{1}{ }^{1, \mathrm{a}}$, Yongxin Yang ${ }^{2, \mathrm{a}}$, Bin $\mathrm{Wu}^{3}$, Haishan Zheng ${ }^{3}$, Liyue $\mathrm{Hao}^{4}$, Tianxiong $\mathrm{Wang}^{4}$, Zhonghua Tao ${ }^{4}$, Yan Tang ${ }^{4 *}$

\title{
Affiliations:
}

* Corresponding author. Correspondence: tangyan200310@163.com

E-mail addresses:

Xiabin Li: 1xb 23@163.com

Yongxin Yang: 596449828@qq.com

BinWu: wwbb129@sina.com

Haishan Zheng: 783737210@qq.com

Liyue Hao: 785939549@qq.com

Tianxiong Wang:1019634382@qq.com

Zhonghua Tao: 22695745@qq.com

Yan Tang: tangyan200310@163.com

a. Xiabin Li and Yongxin Yang contributed equally to this work.

1. Department of Pathology, the First Affiliated Hospital of Southwest Medical University, 25

Taiping Road, Luzhou, 646000 Sichuan, China.

2. Hospital Infection Management Department, Guizhou Qiannan People's Hospital, 9 Wenfeng Road, Duyun, 558000 Guizhou, China.

3. Department of Breast Surgery, First Affiliated Hospital of Southwest Medical University, 8 Kangcheng Road, Luzhou, 646000, China.

4. Public Health Experimental Teaching Center, School of Public Health, Southwest Medical University, 1 Xianglin Road, Luzhou, Sichuan, 646000, China.

\section{The precise word count:}

Excluding References:5404

Including References: 6263

\begin{abstract}
To explore the role of DNA repair gene ERCC1 in breast cancer metastasis and its signaling pathway.Through prospective cohort studies and cell tests, Western Blot and IHC were used to detect the expression of DNA repair gene ERCC1 and NF- $\mathrm{KB}$ signaling pathways related proteins, scratch test and Transwell to detect the ability of migration and invasion. To explore the mechanism of ERCC1 affecting breast cancer metastasis. Population results: There was no significant difference in clinicopathological features between the two groups $(P>0.05)$. ERCC1 has a positive correlation with breast cancer metastasis $(r=0.543, P<0.05)$. And the metastasis-free survival rate of ERCC1 low expression group was higher than that of high expression group $\left(\chi^{2}=17.571, P<0.05\right)$. The expression level of $\mathrm{p} 65, \mathrm{p} 50, \mathrm{TNF} \alpha, \mathrm{IKK} \beta$ in ERCC1 low expression group was significantly lower than that in ERCC1 high expression group $(P<0.05)$, $\mathrm{I \kappa B} \alpha$ was significantly higher than ERCC1 high expression $\operatorname{group}(P<0.05)$. The analysis of Spearman correlation method shows that ERCC1 expression is positively correlated with the
\end{abstract}


$\operatorname{IKK} \beta(r=0.481, P<0.05), \operatorname{IKK} \beta$ and $\operatorname{I\kappa B} \alpha$ were negatively correlated $(r=-0.203, P<0.05)$, IאB $\alpha$ and p50 were negatively $\operatorname{correlated}(r=-0.275, P<0.05)$, p50 and p65 were positively correlated $(r=0.386, P<0.05)$, positive correlation between p65 and TNF $\alpha(r=0.476, P<0.05)$, $\mathrm{TNF} \alpha$ is positively associated with breast cancer metastasis $(r=0.281, P<0.05)$. Cell tests:At 24 hours, the migration distance of the MCF-7-ERCC1 knockdown group was less than that of the negative control group $(P<0.05)$. At 48 hours, the migration distance of MCF-7-ERCC1 knockdown group was less than that of blank control group and negative control group $(P<0.05)$. Compared with the blank control group and the negative control group, the number of cell invasion in the MCF-7-ERCC1 knockdown group decreased significantly $(P<0.001)$. Compared with the blank control group, the number of cell invasion decreased in the negative control group $(P<0.05)$. The protein level of p65, p50, TNF $\alpha$, IKK $\beta$ in ERCC1 knockdown group was significantly lower than that in blank control group and negative control group $(P<0.05)$, ІкB $\alpha$ protein levels were significantly higher than those of the blank and negative control groups $(P<0.05)$. DNA repair gene ERCC1 may affect breast cancer metastasis by regulating NF-kB signaling pathways.

Key words: ERCC1; Breast Cancer; metastasis; NF- $\kappa B$ signaling pathways

Breast cancer is a very high incidence of malignant tumors, among American women, it ranks first in the mortality of malignant tumors ${ }^{1}$. The study found that breast cancer metastasis is closely related to the regulatory system of DNA repair. In clinical treatment of tumors, related drugs are usually used to destroy their cell DNA, thus inducing apoptosis to eliminate cancer cells $^{2-3}$.However, some tumor cells can induce metastasis by activating DNA repair ${ }^{4}$ 。

ERCC1 is a DNA repair gene, located on autologous chromosome 19 and containing 10 exons, which can encode ERCC1 proteins and act as structure-specific endonuclease in NER. NER pathways identify DNA damage by GG-NER or TC-NER and recruit multiple related factors, ERCC1/XPF bind to the 5' end of the damaged single strand and cut the DNA chain, remove the 25-30 nucleotide long oligonucleotides containing the damaged DNA, repair the nucleotide defects with DNA polymerase, and finally repair the nucleotide defects with DNA ligase $^{5}$.Furthermore, ERCC1 also plays an important role in some aspects as inter-chain cross-linking repair, double-strand break repair and telomere maintenance. DSB is a severe DNA injury that can lead to cell death, genomic alterations, and tumor formation.

A number of clinical studies have confirmed that the expression level of ERCC1 is closely related to the efficacy and prognosis of platinum-containing chemotherapy in tumor patients.Metro $\mathrm{G}^{6}$ pointed out that in breast cancer, the efficacy of ERCC1 expressed in platinum-containing chemotherapy regimen was negatively correlated. Kasimir ${ }^{7}$ study found that patients with low ERCC1 expression were more likely to benefit from chemotherapy regimens containing platinum-based therapy drugs, while low ERCC1 expression in invasive breast cancer has been found to be associated with negative lymph node status. Abdel ${ }^{8}$ and other examined the relationship between ERCC1 expression and chemotherapy in breast cancer, showed that patients with negative ERCC1 expression had higher chemotherapy efficiency. Xiaosong Chen's ${ }^{9}$ study found that ERCC1 was an independent predictor of complete pathological remission in breast cancer patients receiving paclitaxel combined with carboplatin weekly regimen neoadjuvant chemotherapy, and the rate of complete pathological remission was higher in ERCC1 negative patients.EL Baiomy Mohamed Ali et a ${ }^{10}$ studies showed that the expression and survival time ERCC1 advanced triple negative breast cancer were negatively correlated with platinum effect. Above studies show that ERCC1 has a certain role in breast cancer resistance, its high expression suggests that chemotherapy effect is poor. 
Current studies have found that ERCC1 expression is associated with cancer metastasis, Jianmin $\mathrm{Fu}^{11}$ found that the expression level of ERCC1 in breast cancer was associated with lymph node metastasis in unchemotherapy group. Ma Wang ${ }^{12}$ study found that the overall survival rate of ERCC1 negative expression was significantly higher than that of patients with positive expression. The higher the TNM stage and lymph node metastasis, the higher the positive predictive value of ERCC1 expression, which suggests a positive correlation between ERCC1 expression and tumor invasiveness and poor prognosis, consistent with studies such as $\mathrm{Ota}^{13}$. He Lang ${ }^{14}$ study found that ERCC1 highly expressed tumor tissue enhanced DNA injury repair and tumor more invasive. Xia Anzhou ${ }^{15}$ study found that adjuvant chemotherapy can reduce ERCC1 and inhibit tumor invasion and metastasis, suggesting that ERCC1 may be associated with tumor metastasis. Wang Yan ${ }^{16}$ study found that ERCC1 expression rate in esophageal squamous cell carcinoma was associated with tumor differentiation, lymph node metastasis, ERCC1 tumor recurrence and distant metastasis. Steffensen ${ }^{17}$ study found that the PFS and OS of patients with ERCC1 positive expression in ovarian cancer were lower than those in the negative expression group, and Hui $\mathrm{EP}^{18}$ found that ERCC1 can repair the damage of tumor cells DNA and reduce the body's autoimmune ability to remove cancer cells, so that ovarian cancer cells from macrophages, $\mathrm{T}$ lymphocytes and natural killer cells,which will lead to the continuous proliferation and metastasis of cancer cells in the cancer tissue of ovarian cancer patients, and then make the patient's condition deteriorate, suggesting that high level of ERCC1 can promote the proliferation, expansion and metastasis of tumor cells, and make the patients more prone to recurrence and after operation $^{19}$. But the relationship between ERCC1 and metastasis in breast cancer is rarely studied.

Some studies have found that cancer cell DNA repair is closely related to IKK $\beta$, when drugs in cancer cells cause DNA damage, ATM is activated as the main kinase in many signal transduction pathways. It is involved in cell cycle checkpoint and repair signal network after DNA injury. IKK $\beta$ plays an important role in NF- $\mathrm{KB}$ pathway. Although there are several signal sources upstream, they all converge on the IKK. generally, the NF- $\mathrm{KB}$ in the cytoplasm is in a state of inactivation due to its dimerization binding NF- $\mathrm{KB}$ inhibiting protein formation of a

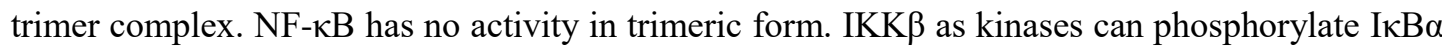
proteins, causing it to dissociate from trimers, NF- $\mathrm{kB}$ dimers can be exposed and rapidly enter the nucleus from the cytoplasm, binding to specific sequences on nuclear DNA, and promoting transcription of related genes ${ }^{20}$. The activated IKB $\alpha$ is combined with $\mathrm{p} 65 / \mathrm{p} 50$ to repair DNA injury. In ovarian and lung adenocarcinoma, overexpression of p65/50 leads to rapid repair of cell injury at the G2/M stage, resulting in tumor necrosis factor TNF- $\alpha$, which stimulates epithelial mesenchymal transformation to produce cancer cell metastasis, and repair the TNF- $\alpha$ caused by DNA injury can produce positive feedback on the NF- $\mathrm{kB}$ pathway and activate the pathway continuously, studies have shown that blocking NF- $\mathrm{kB}$ pathways attenuates MCF-7 cell invasion and migration ${ }^{21}$.

Therefore, in this study, patients with breast cancer in affiliated hospitals were studied, through in vitro cell tests and population cohort studies, Western Blot and IHC methods were used to detect the expression of DNA injury repair gene ERCC1 and NF- $\mathrm{kB}$ pathway related proteins. To explore the mechanism of postoperative metastasis and provide important scientific basis for the prevention of postoperative metastasis and survival rate.

Methods

1 Population aspects 


\subsection{Follow-up cohort}

A follow-up cohort of breast cancer patients was established after the first confirmed operation in the affiliated Hospital of Southwest Medical University. The cohort was established in January 2013 and included in the study year by year. At present, there are 1360 patients in the cohort, who visit each year. Inclusion criteria: primary breast cancer patients diagnosed by pathological diagnosis after surgery, followed up for 5 years, the main treatment methods and chemotherapy methods are the same, pathological data are complete, and breast cancer metastasis as the outcome. Exclusion criteria: follow-up less than 5 years, pathological data is not complete, breast cancer recurrence or metastasis with recurrence or death as the outcome. Ethical question : patient informed consent to participate. The research plan was approved by the Biomedical Ethics Committee of Southwest Medical University and met the ethical requirements of clinical research. Application No.: XNYD2018001.

\subsection{Determination of grouping and sample size}

Based on the previous research results ${ }^{22}$, the ERCC1 IHC score was 3 as critical value, more than 3 as high expression group, less than 3 as low expression group. On the basis of metastasis rate of ERCC1 patients with high expression was $p_{I}=0.643$, that of ERCC1 patients with low expression was $p_{0}=0.175 ; \alpha=0.05, \beta=0.10$. Sample content formula based on cohort study(1) and calculated samples $n=63$.

$$
n=\left[\frac{\left(\mathrm{Z}_{\alpha / 2} \sqrt{2 \bar{p} \bar{q}}+\mathrm{Z}_{\beta} \sqrt{p_{0} p_{1}+q_{0} q_{1}}\right)}{p_{1}-p_{0}}\right]^{2}
$$

\subsection{Data collection}

The clinicopathological data (clinical data, pathological data and treatment plan) used in the study were from the Department of Pathology and Breast surgery of the affiliated Hospital of Southwest Medical University; The paraffin samples of breast cancer patients were from the pathology department, and the paraffin block samples were 100\% tumor cells (determined by the pathologist).

\subsection{Measurement of ERCC1 and NF-KB signaling pathway-related proteins in paraffin blocks of breast cancer patients}

Paraffin sections $(3 \mu \mathrm{m})$ were dried, deparaffined, and rehydrated in graded alcohol to water. Heat-mediated antigen retrieval was performed using pressure cooker treatment for 10min in EDTA buffer (PH 9.0). The slides were incubated for $120 \mathrm{~min}$ at $25^{\circ} \mathrm{C}$ with primary mouse anti-human polyclone antibodies to $\mathrm{p} 65, \mathrm{p} 50, \mathrm{IKK} \beta, \mathrm{TNF} \alpha, \mathrm{I} \kappa \mathrm{B} \alpha$. After washing, the sections were incubated with the second antibody (Envision, HRP rabbit/mouse, Dako, DK) for $30 \mathrm{~min}$ at $25^{\circ} \mathrm{C}$. Negative controls were obtained by omitting the primary antibody. The slides were visualized by DAB.

Expression of NF- $\mathrm{kB}$ signaling pathways was determined in the nucleus of tumor cells. Five high-power fields $(200 \times)$ were randomly selected. The extent of the staining was categorized into five semi-quantitative classes based on the percentages of positive tumor cells: $0,<5 \%$ positive cells; $1,6-25 \%$ positive cells; $2,26-50 \%$ positive cells; $3,51-75 \%$ positive cells; and $4,>75 \%$ positive cells. Staining intensity was scored as 0 , negative; 1 , weak; 2 , moderate; and 3, intensive. Multiplication of the intensity and the percentage scores gave rise to the final staining score. The review process is done independently by two senior pathologists in a double-blind manner, and the superior physician will again judge any dissenting cases to ensure that the results are accurate.

\section{Cell testing}




\subsection{Cell lines}

The breast cancer cell lines with ERCC1 gene expression were queried in the https://www.proteinatlas.org/, and the MCF-7 cell lines with high expression and more research in breast cancer metastasis and invasion were selected. Human breast cancer cell line MCF-7 borrowed from the Institute of Oncology, Southwest Medical University. The human breast cancer cell line MCF-7-ERCC1 knockdown lentivirus stable strain and MCF-7-NC negative control were purchased from Shanghai Hanheng Biotechnology Co., Ltd.

\subsection{ERCC1 knockdown expression plasmid}

The ERCC1 knockdown plasmid was designed and synthesized by Shanghai Hanheng Biotechnology Co., Ltd. The human breast cancer cell lines MCF-7 cells transfected with ERCC1 knockdown plasmid were stored in $-80^{\circ} \mathrm{C}$ refrigerator.

(1)Carrier: pHBLV-U6-MCS-CMV-ZsGreen-PGK-PURO;

(2)Knockdown target design and primer sequences:

\begin{tabular}{ll}
\hline Gene & Primer sequences \\
\hline ERCC1 siRNA & CCTCAAGGAGCTGGCTAAGATGTGT \\
ERCC1-shRNA & GATCCGCCTCAAGGAGCTGGCTAAGATGTGTTTCAAGAGA 1 ACACAT \\
(Top strand) & CTTAGCCAGCTCCTTGAGGTTTTTTG \\
ERCC1-shRNA & AATTCAAAAAACCTCAAGGAGCTGGCTAAGATGTGTTCTCTTGAA - \\
(Bottom strand) & CACATCTTAGCCAGCTCCTTGAGGCG
\end{tabular}

\subsection{RT-qPCR}

Total RNA were extracted using the RNeasy FFPE Kit (QIAGEN, shanghai, China), according to manufacturer's instructions. cDNA was reversely transcribed using the PrimeScript RT reagent Kit with gDNA Eraser (TaKaRa, Dalian, Liaoning, China).Gene expression was quantified by SYBR Premix Ex Tap II (TaKaRa, Dalian, Liaoning, China) and performed in a real-time thermal cycler qTOWER 2.0/2.2 (Analytik Jena, Germany) Relative gene expression was calculated using the $2^{-\Delta \mathrm{CT}}$ method and the results were normalized with $\beta$-actin as an internal control. The primer sequences are shown in Table 1.

Table.1 The primers used for PCR

\begin{tabular}{ll}
\hline Primer Name & Primer Sequence \\
\hline ERCC1-F & GCGACGTAATTCCCGACTA \\
ERCC1-R & CCGCTGGTTTCTGCTCAT \\
GAPDH-F & TCAAGGCTGAGAACGGGAAG \\
GAPDH-R & TCGCCCCACTTGATTTTGGA \\
\hline
\end{tabular}

\subsection{Western Blot}

Stable transfection ERCC1 knockdown, using RIPA lysis buffer (Bioteke,Wuxi) to cleave three groups of MCF-7 cell proteins. Protein concentration was determined by BCA method.Proteins were separated and transferred to the PVDF membrane(Millipore) by $10 \%$ SDS-PAGE and then incubated overnight with the following antibody at $4^{\circ} \mathrm{C}$.The membrane was incubated with horseradish peroxidase labeled goat anti-rabbit $\mathrm{IgG}$ (Bioss,Beijing) for $2 \mathrm{~h}$ at room temperature. GAPDH as internal control. A ECL method is used to develop and capture the generated image using a digital imaging system. The diluted antibodies ratio in this part of the experiment of proportion is as follows:

\begin{tabular}{cc}
\hline Antibody, manufacturer & Optimal dilution ratio \\
\hline$\beta$-actin,Cell Signaling Technology & $1: 2000$
\end{tabular}




$\begin{array}{cc}\text { ERCC1,Proteintech } & 1: 2000 \\ \text { TNF- } \alpha \text {,AtaGenix } & 1: 1000 \\ \text { IKB } \alpha, \text { Abcam } & 1: 10000 \\ \text { IKK } \beta \text {,AtaGenix } & 1: 1000 \\ \text { p65,Abcam } & 1: 2000 \\ \text { p50,Abcam } & 1: 1000 \\ \text { Goat Anti-Rabbit IgG/HRP } & 1: 7000\end{array}$

\subsection{Cellular scratches}

The samples that have been successfully established and identified by the RT-qPCR and Western blot are added to the plate hole, and the stage of the cells is paid attention to, the quantity is controlled to ensure the sufficient reaction source; the changes in the template are observed, once the cells are fused, the tool is the gun head and the bottom area; and use PBS wash twice to remove suspended cells; add medium containing 1\% FBS to culture; observe, photograph and detect scratch healing at different time points to judge cell motility. Each time three scratch fields were taken, the average distance was calculated using ImageJ, and repeated 3 times to evaluate cell migration ability.

\subsection{Transwell}

Preparation Corning Costar Transwell (24 holes ,8 $8 \mu \mathrm{m}$ diameter); Spread 1:8 Matrige gel diluted without serum medium, logarithmic cells were starved in serum-free medium for 12 hours, then digest and re-suspend cells in serum-free medium, and then inoculated in the upper chamber $\left(200 \mu 1,4 \times 10^{4}\right.$ per hole). Next put $600 \mu 1$ complete medium containing FBS in the lower chamber and place it in incubator $24 \mathrm{~h}$.

\section{Statistical analysis}

Data was double entered and checked by Epidata3.1 software.Apply SPSS25.0 statistical software for statistical analysis. The measured data in accordance with the normal distribution are expressed as mean \pm standard deviation $(\bar{X} \pm S)$, and the median and quartile range are expressed as not in accordance with the normal (Median $(I Q R))$. When comparing the two independent samples, if the normal distribution and variance are uniform, the $t$ test is adopted, and the Mann-Whitney $U$ test is used if the normal distribution is not consistent. When comparing paired samples, the paired $t$ test is used for normal distribution, and the Wilcoxon paired symbol rank test is used for non-normal distribution. To analyze the correlation between the two groups of quantitative data, the use Pearson correlation analysis with normal distribution, and the Spearman grade correlation for those without normal distribution. The analysis was used for survival analysis, Cox risk regression model was used for multivariate analysis, $P<0.05$ was statistically significant.

\section{Results}

\section{Population aspects results}

\subsection{Comparison of pathological characteristics of two group patients}

The pathological characteristics analysis showed that there was no significant difference between the pathological characteristics of all breast cancer patients in ERCC1 low expression group and the expression of breast cancer patients in ERCC1 high expression group $(P>0.05)$, see Table 2.

Table 2 Analysis of pathological characteristics of two groups (n(\%)) 


\begin{tabular}{|c|c|c|c|c|c|}
\hline $\begin{array}{l}\text { Pathological } \\
\text { characteristics }\end{array}$ & $n$ & Low ERCC1 & High ERCC1 & $\chi^{2}$ & $P$ \\
\hline \multicolumn{6}{|l|}{ Age (years) } \\
\hline $0 \sim$ & 59 & $30(47.6)$ & $29(46.0)$ & \multirow{2}{*}{0.032} & \multirow{2}{*}{0.858} \\
\hline $50 \sim$ & 67 & $33(52.4)$ & $34(54.0)$ & & \\
\hline \multicolumn{6}{|l|}{ ER } \\
\hline Negative & 47 & $23(36.5)$ & $24(38.1)$ & \multirow{2}{*}{0.034} & \multirow{2}{*}{0.854} \\
\hline Positive & 79 & $40(63.5)$ & $39(61.9)$ & & \\
\hline \multicolumn{6}{|l|}{ PR } \\
\hline Negative & 65 & $30(47.6)$ & $35(55.5)$ & \multirow{2}{*}{0.749} & \multirow{2}{*}{0.373} \\
\hline Positive & 61 & $33(52.4)$ & $28(44.5)$ & & \\
\hline \multicolumn{6}{|l|}{ HER2 } \\
\hline$-/+$ & 89 & $41(65.1)$ & $48(76.2)$ & \multirow{2}{*}{1.875} & \multirow{2}{*}{0.171} \\
\hline+++ & 37 & $22(34.9)$ & $15(23.8)$ & & \\
\hline \multicolumn{6}{|l|}{ E-Cad } \\
\hline Negative & 15 & $7(11.1)$ & $8(12.7)$ & \multirow{2}{*}{0.076} & \multirow{2}{*}{0.783} \\
\hline Positive & 111 & $56(88.9)$ & $55(87.3)$ & & \\
\hline \multicolumn{6}{|l|}{ P53 } \\
\hline Negative & 76 & $39(61.9)$ & $37(58.7)$ & \multirow{2}{*}{0.133} & \multirow{2}{*}{0.716} \\
\hline Positive & 50 & $24(38.1)$ & $26(41.3)$ & & \\
\hline \multicolumn{6}{|l|}{ Ki67 } \\
\hline $0 \sim$ & 36 & $19(30.1)$ & $17(27.0)$ & \multirow{2}{*}{0.156} & \multirow{2}{*}{0.693} \\
\hline $20 \sim$ & 90 & $44(69.9)$ & $46(73.0)$ & & \\
\hline \multicolumn{6}{|l|}{ Molecular subtypes } \\
\hline Luminal A & 24 & $14(22.2)$ & $10(17.5)$ & \multirow{5}{*}{2.639} & \multirow{5}{*}{0.620} \\
\hline Luminal B & 37 & $21(33.3)$ & $16(28.1)$ & & \\
\hline Luminal HER2 & 21 & $8(12.7)$ & $13(22.8)$ & & \\
\hline HER2-enriched & 10 & $6(9.5)$ & $4(7.0)$ & & \\
\hline Basal-like & 28 & $14(22.2)$ & $14(24.6)$ & & \\
\hline \multicolumn{6}{|l|}{ Lymph node metastasis } \\
\hline 0 & 48 & $25(39.7)$ & $23(36.5)$ & \multirow{4}{*}{0.932} & \\
\hline $1 \sim$ & 23 & $13(20.6)$ & $10(15.9)$ & & 0.818 \\
\hline $4 \sim$ & 24 & $11(17.5)$ & $13(20.6)$ & & \\
\hline $10 \sim$ & 31 & $14(22.2)$ & $17(27.0)$ & & \\
\hline Pathological type & & & & & \\
\hline Carcinoma in situ & 7 & $3(4.8)$ & $4(6.3)$ & & \\
\hline $\begin{array}{l}\text { Non-specific invasive } \\
\text { carcinoma }\end{array}$ & 118 & $59(93.7)$ & $59(93.7)$ & 1.143 & 0.565 \\
\hline $\begin{array}{l}\text { Invasive special type } \\
\text { carcinoma }\end{array}$ & 1 & $1(1.6)$ & $0(0.0)$ & & \\
\hline Tumor size(cm) & & & & & \\
\hline $0 \sim$ & 37 & $19(30.2)$ & $18(28.6)$ & & \\
\hline $2 \sim$ & 71 & $35(55.6)$ & $36(57.1)$ & 0.041 & 0.980 \\
\hline $5 \sim$ & 18 & $9(14.3)$ & $9(14.3)$ & & \\
\hline
\end{tabular}




\begin{tabular}{rccccc}
\hline WHO Grade & & & & & \\
I & 6 & $2(3.2)$ & $4(6.3)$ & & \\
II & 80 & $41(65.1)$ & $39(61.9)$ & 0.717 & 0.699 \\
III & 40 & $20(31.7)$ & $20(31.7)$ & & \\
\hline
\end{tabular}

\subsection{Effects of ERCC1 on breast cancer metastasis}

ERCC1 expression was positively correlated with breast cancer metastasis $(r=0.543$, $P<0.001$ ), see table 3 . The survival rate of breast cancer patients with ERCC1 low expression group was higher than that of ERCC1 high expression group in metastasis-free survival analysis $\left(\chi^{2}=17.571, P<0.001\right)$, see figure 1 .

Table 3 ERCC1 correlation with breast cancer metastasis

\begin{tabular}{ccc}
\hline Variable & ERCC1 & Breast cancer metastasis \\
\hline ERCC1 & 1 & $0.543^{*}$ \\
Breast cancer metastasis & - & 1 \\
\hline
\end{tabular}

Note :* Represents $P<0.05$.

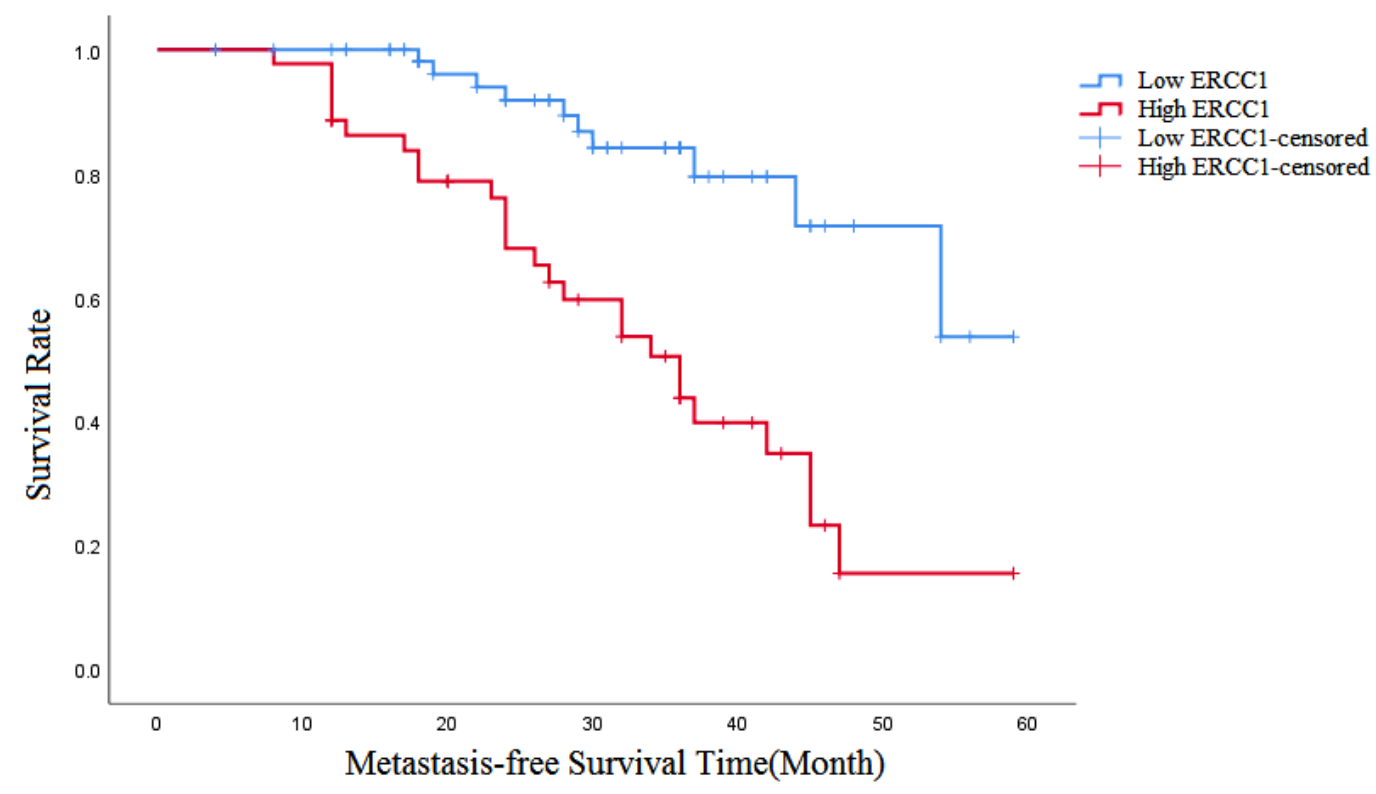

Figure 1 Analysis of metastasis-free survival of breast cancer patients after ERCC1 grouping

\subsection{Comparison of the Expression of NF-kB Signal Pathway-related Protein in two Groups} p65、p50、TNF $\alpha$ IKK $\beta$ IHC positive expression was yellow. The protein level of p65、p50、 TNF $\alpha$, IKK $\beta$ in paraffin block of breast cancer patients with ERCC1 high expression group was significantly higher than that in low expression group $(P<0.05)$, IкB $\alpha$ protein levels were significantly lower than those of low expression groups $(P<0.05)$, see figures 2,3 . 
High ERCC1
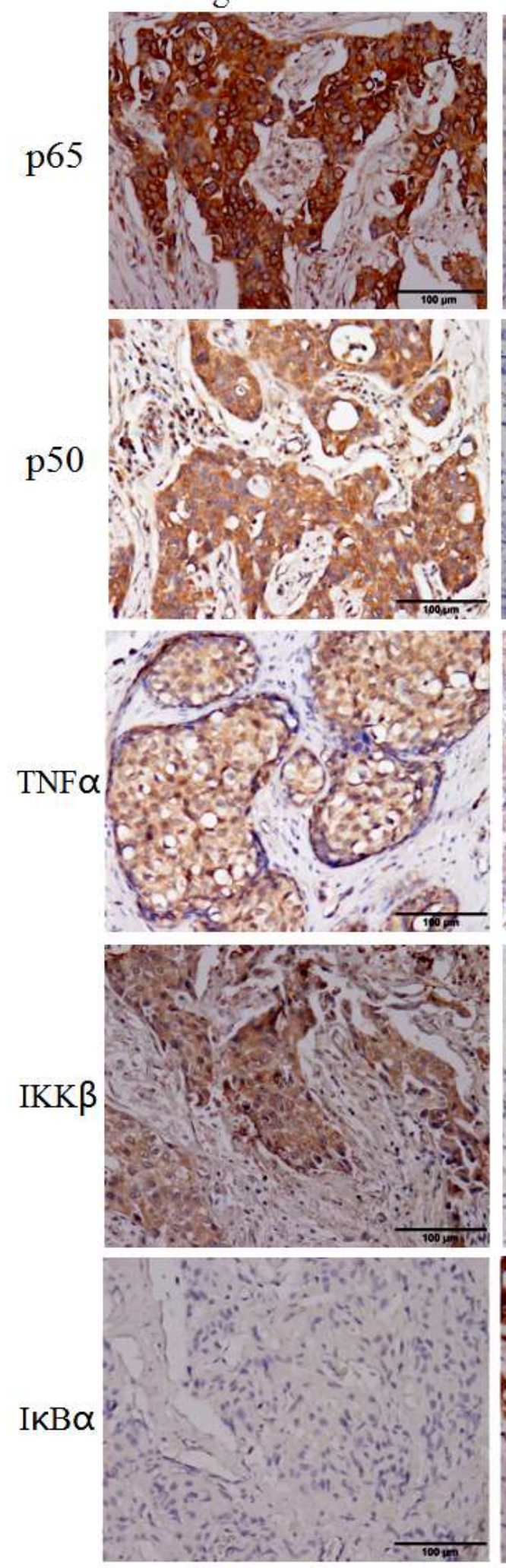

Low ERCC1
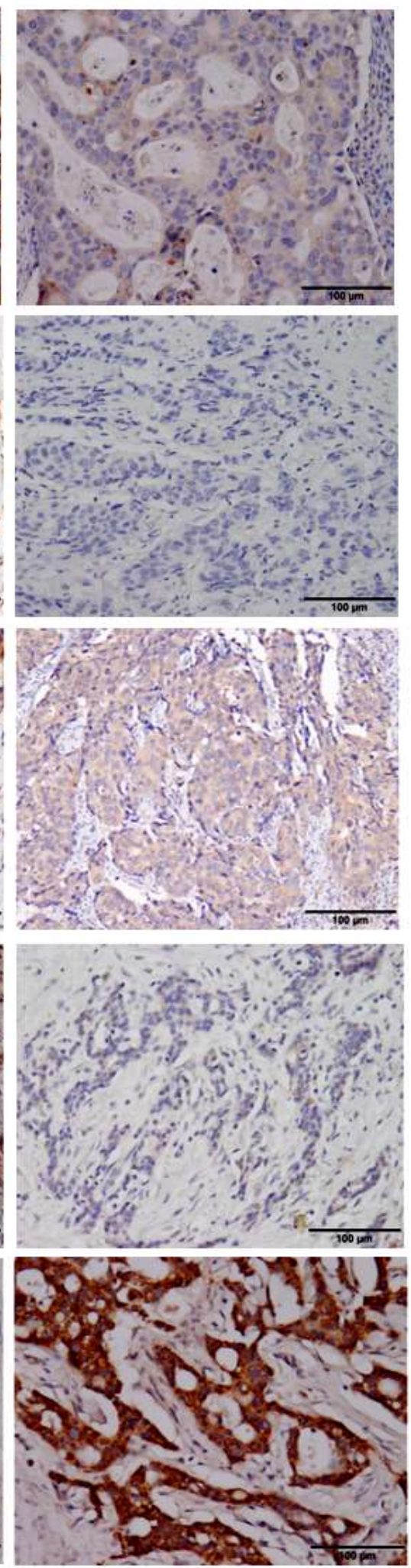

Figure 2 IHC of NF- $\kappa B$ signaling pathway related proteins in breast cancer patients 

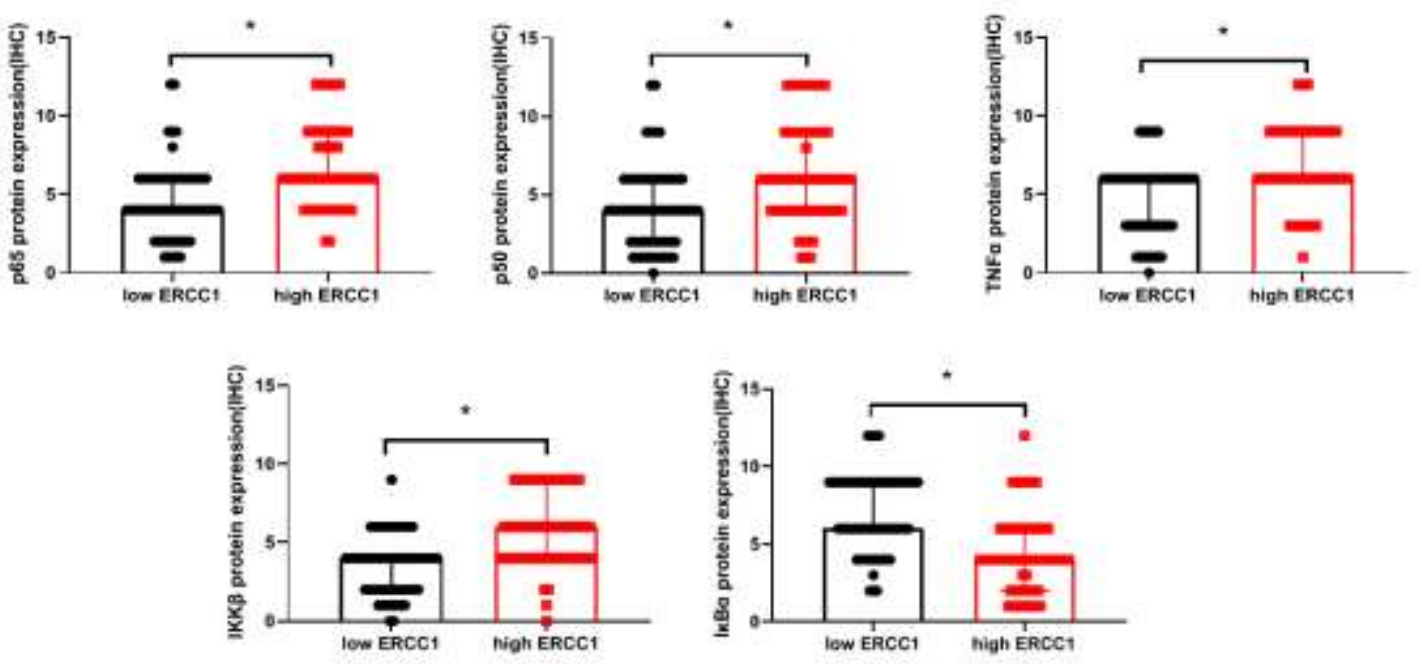

Figure 3 Comparison of NF- $\mathrm{KB}$ signaling pathway-related protein expression in two groups of breast cancer patients(Median(IQR), * Represents $P<0.05$.)

1.4 Correlation between ERCC1-NF-KB signaling pathway factors and breast cancer metastasis

The results showed that ERCC1 expression was positively correlated with IKK $\beta$ expression $(r=0.481, P<0.001)$; IKK $\beta$ and IKB $\alpha$ were negatively correlated $(r=-0.203, P=0.023)$; $\mathrm{I \kappa B} \alpha$ and $\mathrm{p} 50$ were negatively correlated $(r=-0.275, P=0.002)$; Positive correlation between p50 and p65 $(r=0.386, P<0.001)$; Positive correlation between $\mathrm{p} 65$ and TNF $\alpha(r=0.476, P<0.001)$; TNF $\alpha$ is positively associated with breast cancer metastasis $(r=0.281, P=0.001)$, see table 4,5 .

Table 4 ERCC1 correlation with IKK $\beta$

\begin{tabular}{ccc}
\hline Variable & ERCC1 & IKK $\beta$ \\
\hline ERCC1 & 1 & $0.481^{*}$ \\
IKK $\beta$ & - & 1 \\
\hline
\end{tabular}

Note :* Represents $P<0.05$.

Table 5 Correlation between NF-kB signaling pathways and breast cancer metastasis

\begin{tabular}{ccccccc}
\hline Variable & $\begin{array}{c}\text { breast cancer } \\
\text { metastasis }\end{array}$ & $\mathrm{p} 50$ & $\mathrm{p} 65$ & $\mathrm{TNF} \alpha$ & $\mathrm{IKK} \beta$ & $\mathrm{I \kappa B} \alpha$ \\
\hline $\begin{array}{c}\text { breast cancer } \\
\text { metastasis }\end{array}$ & 1 & $0.250^{*}$ & $0.239^{*}$ & $0.281^{*}$ & $0.221^{*}$ & $-0.363^{*}$ \\
p50 & - & 1 & $0.386^{*}$ & $0.424^{*}$ & $0.319^{*}$ & $-0.275^{*}$ \\
p65 & - & - & 1 & $0.476^{*}$ & $0.374^{*}$ & $-0.219^{*}$ \\
TNF $\alpha$ & - & - & - & 1 & $0.453^{*}$ & $-0.224^{*}$ \\
IKK $\beta$ & - & - & - & - & 1 & $-0.203^{*}$ \\
IкB $\alpha$ & - & - & - & - & - & 1 \\
\hline
\end{tabular}

Note :* Represents $P<0.05$. 


\section{Cellular aspects}

2.1 ERCC1mRNA and protein expression of stable transfection of ERCC1 knockdown MCF-7 cells

The results showed that the ERCC1mRNA in MCF-7-ERCC1 knockdown group was significantly lower than that in MCF-7-NC negative control group $(P<0.05)$; ERCC1 protein levels in MCF-7-ERCC1 cells decreased significantly compared with those in MCF-7-NC negative control group and MCF-7 blank control group $(P<0.05)$, see figure 4; These results suggest that the ERCC1 expression in the MCF-7 can be effectively disturbed and subsequent experiments can be carried out.

A

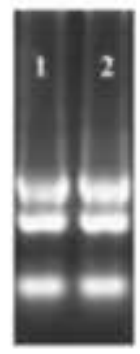

1: MCF-7-NC

2: MCF-7-ERCCI

C

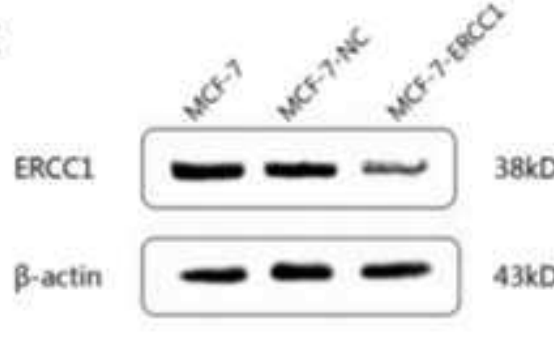

B

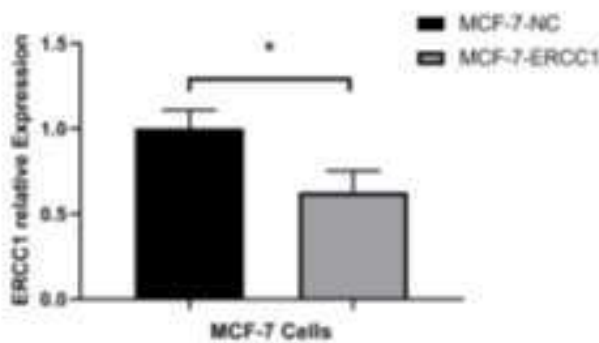

D

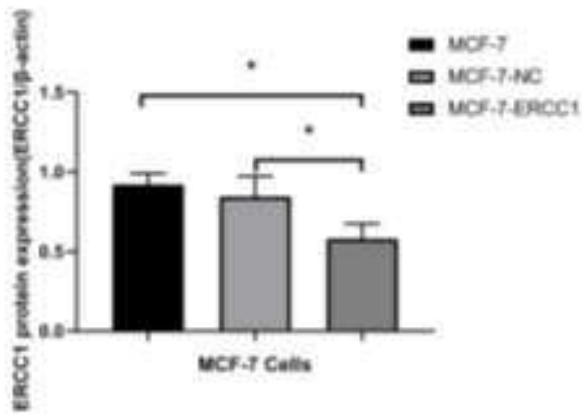

Figure 4 Transfection efficiency of MCF-7 cell lines with stable knockdown ERCC1

(* Represents $P<0.05$ ) (A)\&(B): RT-qPCR ;(C)\&(D): Western Blot

\subsection{The detection of migration ability of MCF-7 cells with stable knockdown ERCC1 in} vitro

At 24 hours, the migration distance of the MCF-7-ERCC1 knockdown group was less than that of the negative control group $(P<0.05)$, compared with the blank control group, the migration distance of the MCF-7-ERCC1 knockdown group was not different $(P>0.05)$. At 48 hours, the migration distance of MCF-7-ERCC1 knockdown group was less than that of blank control group and negative control group $(P<0.05)$, as show in figure 5,6. 


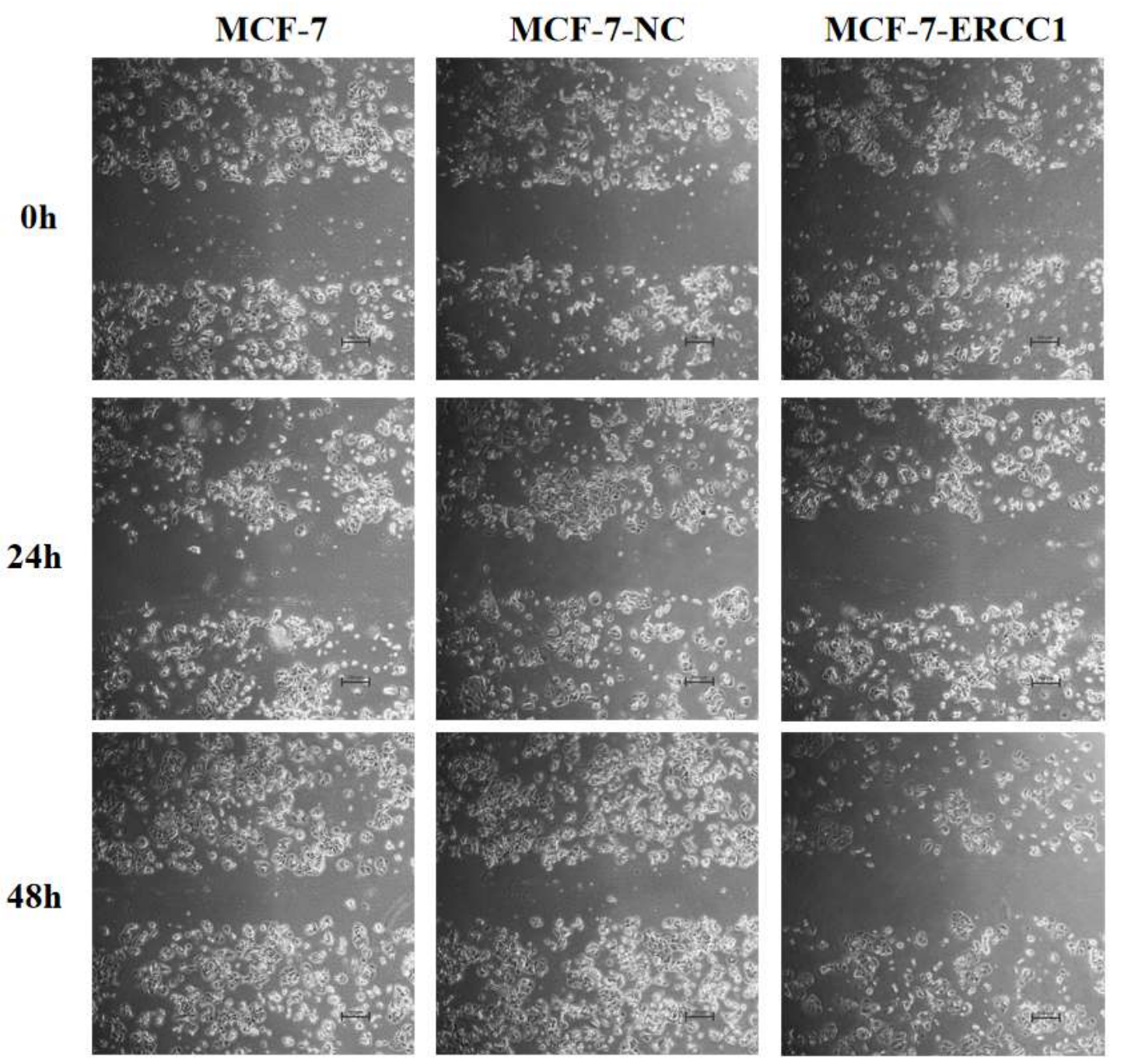

Figure 5 Scratch test of low ERCC1 MCF-7 breast cancer cell line migration in vitro

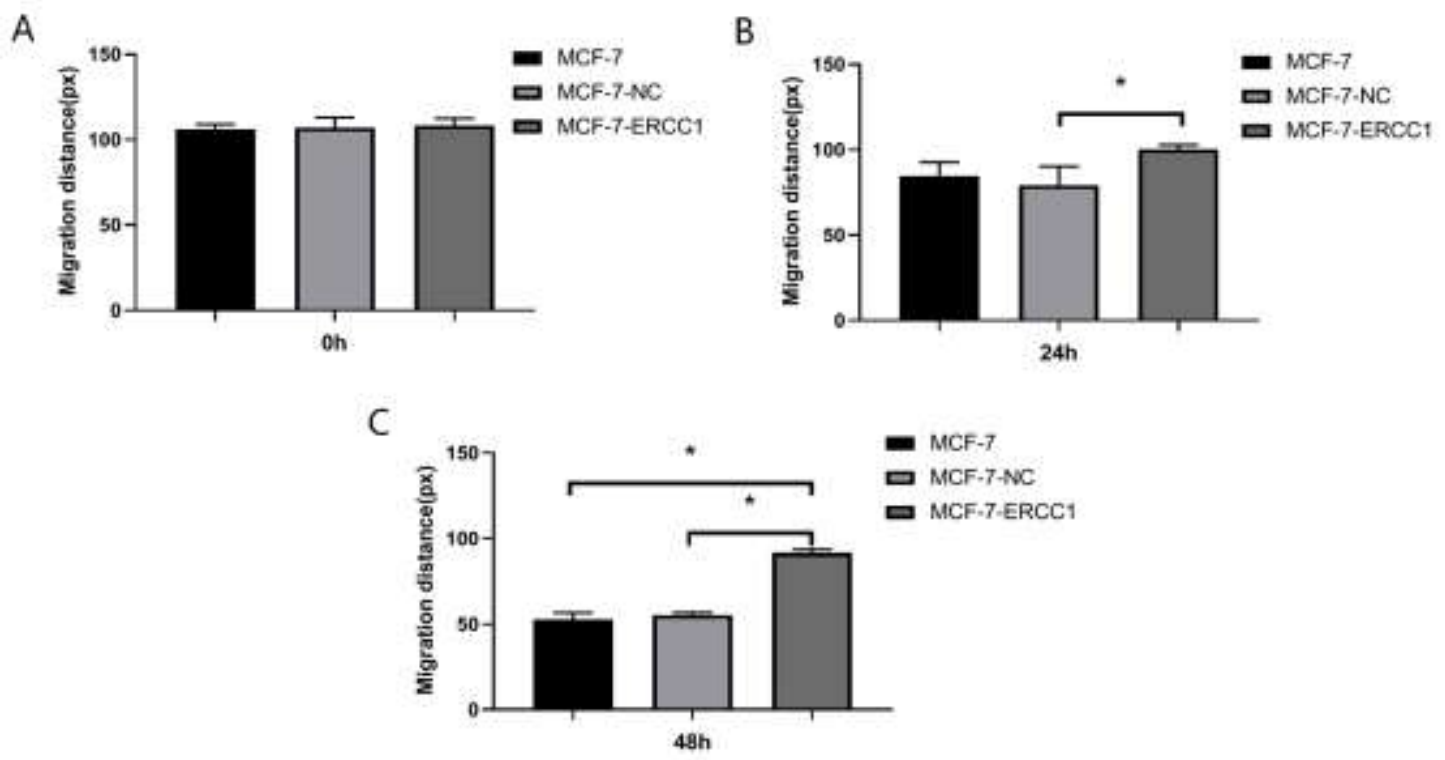

Figure 6 The Comparison of Mean Scratch Width of MCF-7 Breast Cancer Cell Lines with 
Stable ERCC1 Knockdown ( * Represents $P<0.05)(\mathrm{A}): 0$ h; (B)24 h; (C):48h

\subsection{The Detection of Invasion Ability of MCF-7 Cells with Stable and ERCC1 Knockdown}

Compared with the blank control group and the negative control group, the number of cell invasion in the MCF-7-ERCC1 knockdown group decreased significantly $(P<0.05)$; compared with the blank control group, the number of cell invasion decreased in the negative control $\operatorname{group}(P<0.05)$, see figure 7 .

A MCF-7

MCF-7-NC

MCF-7-ERCC1
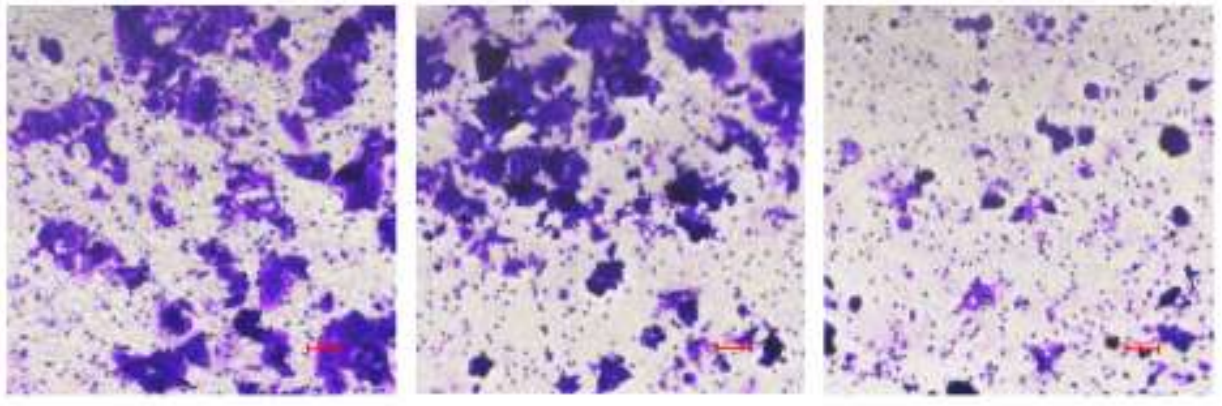

B
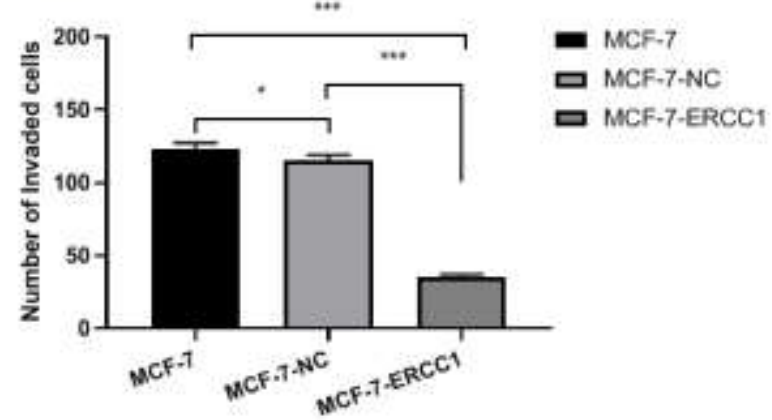

Figure 7 Detection of invasive ability in vitro of MCF-7 breast cancer cell lines with stable knockdown ERCC1; ( Note :* means $P<0.05$ )

\subsection{The affect of ERCC1 on NF-кB signaling pathways}

The protein level of $\mathrm{p} 65, \mathrm{p} 50 、 \mathrm{TNF} \alpha 、 \mathrm{IKK} \beta$ in ERCC1 knockdown group was significantly lower than that in blank control group and negative control group $(P<0.05)$, IкB $\alpha$ protein levels were significantly higher than those of the blank and negative control groups $(P<0.05)$, see figure 8 . 

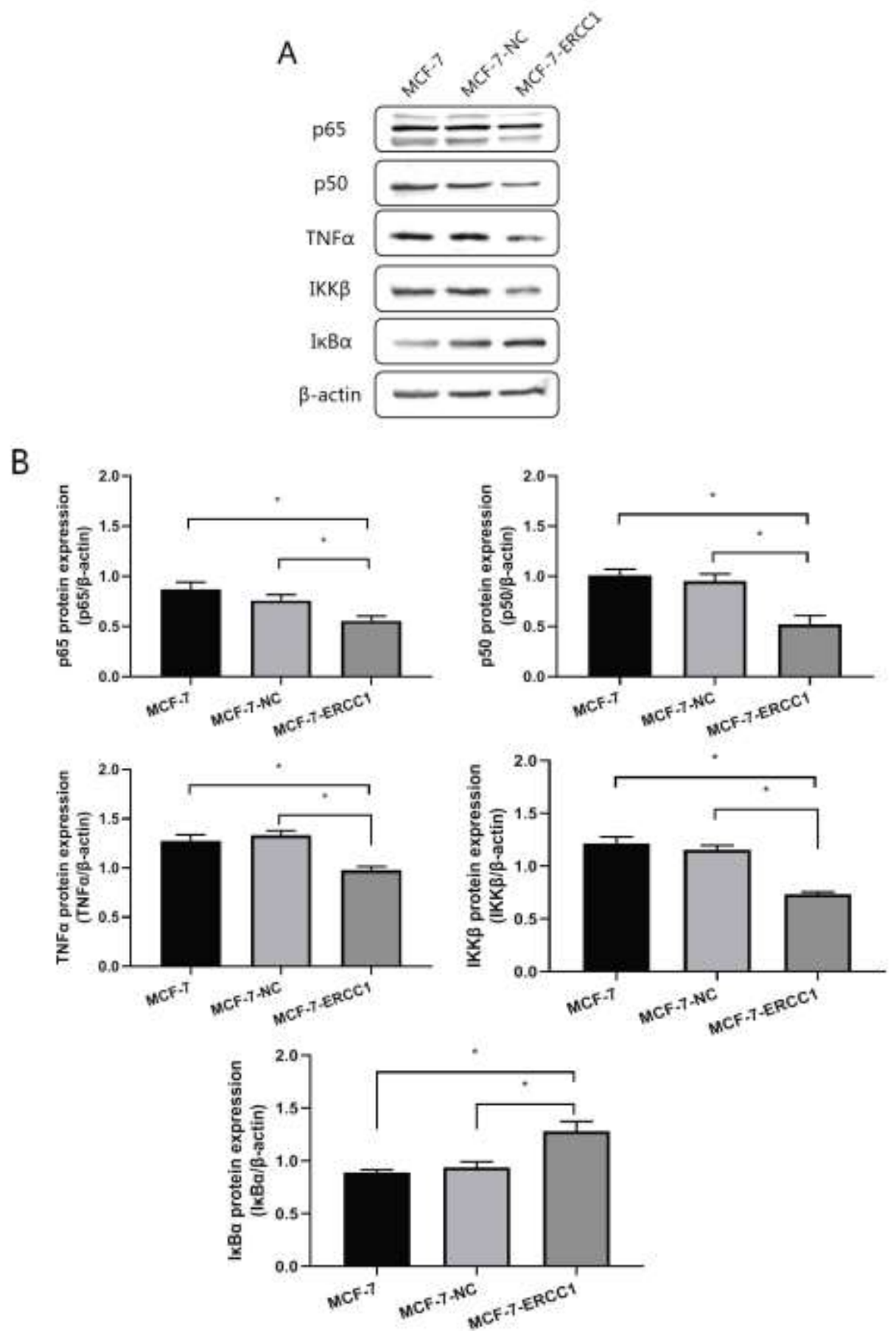

Figure 8 Stable knockdown ERCC1 expression of key factors in NF- $\mathrm{kB}$ signaling pathway in MCF-7 cells(Note :* Represents $P<0.05)(\mathrm{A})$ : Western Blot electrophoresis; (B): Western Blot electrophoresis protein grayscale analysis

\section{Discussion}

The survival analysis of 63 pair patients with ERCC1 high expression group and ERCC1 low expression group showed that the survival rate of ERCC1 high expression group was significantly lower than that of ERCC1 low expression group. The results were consistent with those reported Huang et $\mathrm{a}^{23}$. It suggested that high expression had an effect on postoperative metastasis and poor prognosis.

In addition, in the cell scratch experiment, it was found that only the ERCC1 knockdown 
group was different from the negative control group after $24 \mathrm{~h}$, which may be related to the slower growth of the MCF-7 cell line; therefore, we added the $48 \mathrm{~h}$ group, and after $48 \mathrm{~h}$, the knockdown group different from the blank control group and the negative control group, it shows that the cell line in the knockdown ERCC1 group has a significantly reduced in vitro migration ability; and in the Transwell experiment, it was also found that the knockdown ERCC1 expression group had a lower in vitro invasion ability compared with the blank control group after 24 hours. Compared with the negative control group, it was significantly reduced. The study is consistent with Zhou Yingqiong's ${ }^{24}$ conclusion that downregulation of ERCC1 in ovarian cancer leads to weakened invasion ability. Regarding the difference between the MCF-7 blank control group and the MCF-7 negative control group, we think it may be that the MCF-7 breast cancer cell line grows in clusters and overlaps. Therefore, the staining is prone to overlap staining after crossing the cell, so it is possible cause counting errors.

After confirming the relationship between ERCC1 and breast cancer metastasis, and knocking down ERCC1 will affect breast cancer metastasis, how does ERCC1 affect breast cancer metastasis? A review of related literature ${ }^{22}$ found that ERCC1 may have a certain relationship with $\mathrm{TNF} \alpha$, and studies have also found that cancer cell DNA repair is closely related to IKK $\beta$. Other studie ${ }^{25}$ have shown that blocking the NF- $\mathrm{KB}$ pathway can reduce the invasion and migration ability of MCF-7 cells, and can regulate the IL-4 / mi R-324-5p / CUEDC2 signaling pathway under the action of sinomenine. NF- $\mathrm{KB}$ activity has an inhibitory effect and effectively inhibits the migration and invasion ability of breast cancer cells; therefore, it is speculated that ERCC1 may also affect breast cancer metastasis through the NF- $\mathrm{KB}$ signaling pathway.

When cancer cells suffer DNA damage, they activate ATM, as the main kinase for a large number of signal transduction, ATM can not only participate in the DNA damage repair network, but also participate in cell cycle checkpoints, and through the activation of NEMO, phosphorylated NEMO and IKK $\beta$ In combination, IKK $\beta$ plays a very important role in the NF- $\mathrm{KB}$ pathway. Although there are many upstream signal sources, they all eventually converge to IKK. NF-KB signaling pathway can participate in the pathological process of a large number of diseases, and this signaling pathway is closely related to human immunity and inflammation. Under normal circumstances, the inhibitory protein expressed by non-activated NF- $\mathrm{KB}$ in the cytoplasm can bind to the dimer to form a trimeric complex. In this form, NF- $\kappa B$ has no activity. The kinase IKK $\beta$ can interact with the IKB $\alpha$ protein, dissociate it from the trimer, and participate in the binding of specific sequences on nuclear DNA to promote the transcription of related genes ${ }^{26}$. Activated IкB $\alpha$ combined with p65/p50 repairs DNA damage and produces tumor necrosis factor TNF- $\alpha$, which in turn stimulates cancer cells to undergo epithelial-mesenchymal transition to produce cancer cell metastasis, and TNF- $\alpha$ produced by repairing DNA damage can be used as an upstream stimulation signal activation pathway. The upstream IKK affects the dissociation of IкB $\alpha$ and NF-kB p65/p50, and achieves positive feedback by acting on inflammatory factors, and continuously activates the NF-kB pathway.

In this study, it was found in Western blot experiments that the MCF-7 breast cancer cell line knocked down ERCC1. The levels of p65, p50, TNF $\alpha$ and IKK $\beta$ in the MCF-7 cell ERCC1 knockdown group were lower, while the knockdown group had lower levels of proteins such as $\mathrm{p} 65$, p50, TNF $\alpha$, and IKK $\beta$. On the contrary, I $\mathrm{KB} \alpha$ increased, and the effective trend of the pathway was consistent with that of Al-Sadi ${ }^{27}$, indicating that knocking down ERCC1 has an inhibitory effect on $\mathrm{p} 65$, p50, TNF $\alpha$ and IKK $\beta$, and promotes the expression of IKB $\alpha$. After low ERCC1, the activation of IKK is inhibited, the phosphorylation of IKB $\alpha$ is reduced, and the transcription of NF- $\mathrm{KB}$ is inhibited; and the results of IHC detection in the population are consistent with the results of Western blot detection, and the p65 of breast cancer patients in the low expression group of ERCC1 Compared with the expression levels of breast cancer patients in the ERCC1 high expression group, the expression levels of, p50, TNF $\alpha$ and IKK $\beta$ were 
significantly reduced. The expression levels of breast cancer patients in the ERCC1 low expression group were significantly higher than those in the ERCC1 high expression group. Through research and analysis, it can be found that TNF $\alpha$ can promote the occurrence and development of breast cancer ${ }^{28}$. Inflammatory factors can induce and activate the NF- $\mathrm{kB}$ signaling pathway, which will participate in the inflammatory response after activation, leading to the occurrence and metastasis of tumor cells. Eradication of related research reports shows that NF- $\mathrm{kB}$ can affect the activity of NF- $\mathrm{KB}$ in cancer cells while promoting the metastasis of breast cancer cells. Interfering with the expression of p65 can effectively inhibit its metastasis ${ }^{29}$. After that, we also analyzed the correlation between ERCC1 and the key molecules of the NF- $\mathrm{KB}$ signaling pathway. The results showed that IKB $\alpha, \mathrm{p} 65, \mathrm{p} 50, \mathrm{TNF} \alpha$ and IKK $\beta$ are all related to the expression of ERCC1; and the key molecules of the NF- $\mathrm{BB}$ signaling pathway are related to the breast. Cancer metastasis is also related. Studies ${ }^{30}$ found that inhibiting the activation of p65 can effectively inhibit the proliferation and invasion of MDA-MB-231 cells, suggesting that in breast cancer, ERCC1 may regulate the NF-KB signaling pathway and affect the breast. The role of cancer metastasis. Another study found that most breast cancer patients are often accompanied by chronic inflammation during the development of the disease, and these chronic inflammations will affect cancer cells, and the tumor will metastasize as the cancer cells spread. According to research, TNF $\alpha$ is closely related to the occurrence of cancer. The cells will be analyzed in a large amount in the tumor microenvironment and promote the growth and further spread of cancer cells. Not only that, the cells can also prevent the immune system from recognizing cancer cells and metastasize. Therefore, it can be known that in breast cancer, ERCC1 may have the effect of regulating NF- $\mathrm{KB}$ signaling pathway and affecting metastasis. The NF- $\mathrm{KB}$ signaling pathway is involved in the pathological changes of various diseases in the human body, and can regulate the levels of various cytokines. If ERCC1 has a regulatory effect on various cytokines downstream of this pathway, then ERCC1 inhibitors will affect NF- $\mathrm{kB}$ signaling pathway has a regulatory effect, so as to play a therapeutic role, relieve inflammation, and restore normal human functions.

Considering this reason, clinically, it is possible to analyze the postoperative cell metastasis by detecting the expression level of ERCC1, and to study the development of the patient's condition after breast cancer surgery. In order to prevent breast cancer postoperative metastasis, use the corresponding Molecular targeted drug inhibitor therapy provides theoretical support and provides a scientific basis for improving survival rates.

\section{Conclusions}

DNA repair gene ERCC1 is positively associated with breast cancer metastasis and may affect breast cancer metastasis by regulating NF- $\mathrm{kB}$ signaling pathways.

\section{Limitation and advantage of the study}

This study has a prospective paired case-control research basis with complete data, and on this basis, further uses prospective cohort studies to analyze the impact and correlation of DNA repair genes in breast cancer metastasis, confirming ERCC1 at the population and cell levels Signal pathways affecting breast cancer metastasis. However, this study only explored the impact on the NF-kB signaling pathway, and did not involve other possible pathways; due to funding issues, all breast cancer cell line types inquired were not included, and there was a certain degree of one-sidedness; in the experimental design, we should coupled with animal experiments, we plan to increase animal experiments and verify other signaling pathways that may be related in 
the next step.

\section{Abbreviations}

ERCC1: DNA excision repair cross complementing 1; ER: Estrogen receptor; PR: Progesterone receptor; HER2: humanepidermalgrowthfactorreceptor-2;TNF- $\alpha$ : Tumor necrosis factor- $\alpha$; NF-kB: Nuclear factor-kappa B;NER: Nucleotide excision repair; GG-NER: Global genome NER; TC-NER: Transcription-coupled NER; DSB: Double strand break repair;IHC: immunohistochemistry; Ki67:Nuclear-associated antigen ki67;

\section{Acknowledgements}

We would like to thank all the patients for their contribution in this study.

\section{Authors' contributions}

Y-T designed, guided the study; XB-L, LY-H and TX-W performed the experiments; YX-Y analyzed the data and wrote the paper; B-W, HS-Z and ZH-T collected the samples. The authors read and approved the final manuscript.

\section{Funding}

This work was supported by grants from the Sichuan Science and Technology Plan Project (2015sz0115) and the Luzhou Science and Technology Plan Project (2013LZLY-J37).

\section{Availability of data and materials}

The datasets generated and/or analysed during the current study are not publicly available due our study was at an early stage of the investigation and had entered into a privacy agreement with the patient but are available from the corresponding author on request.

\section{Ethics approval and consent to participate}

Patients with informed consent to participate. The study plan has been reviewed by the Biomedical Ethics Committee of Southwest Medical University, and it is considered to meet the ethical requirements of clinical research, and the study plan is approved. Application acceptance Number: XNYD2018001.

\section{Consent for publication}

All authors agree to submit the article for publication.

\section{Competing interests}

The authors declare that they have no conflicts of interest.

\section{Author details}

1. Department of Pathology, the First Affiliated Hospital of Southwest Medical University, 25 Taiping Road, Luzhou, 646000 Sichuan, China.

2. Hospital Infection Management Department, Qiannan People's Hospital of Guizhou Province, 9 Wenfeng Road, Duyun, 558000 Guizhou, China. 
3. Department of Breast Surgery, First Affiliated Hospital of Southwest Medical University, 8 Kangcheng Road, Luzhou, 646000, China.

4. Breast Surgery, the First Affiliated Hospital of Southwest Medical University, 8 Section 2, Kangcheng Road, Luzhou, 646000 Sichuan, China

5. Public Health Experimental Teaching Center, School of Public Health, Southwest Medical University, 1 Xianglin Road, Luzhou, Sichuan, 646000, China.

\section{Reference}

1.DeSantis Carol E,Ma Jiemin,Gaudet Mia M,Newman Lisa A,Miller Kimberly D,Goding Sauer Ann,Jemal Ahmedin,Siegel Rebecca L. Breast cancer statistics, 2019.[J]. CA: a cancer journal for clinicians,2019,69(6).

2.Nishimura Reiki,Osako Tomofumi,Okumura Yasuhiro et al. Changes in the ER, PgR, HER2, p53 and Ki-67 biological markers between primary and recurrent breast cancer: discordance rates and prognosis.[J] .World J Surg Oncol, 2011, 9: 131.

3.Woditschka Stephan,Evans Lynda,Duchnowska Renata et al. DNA double-strand break repair genes and oxidative damage in brain metastasis of breast cancer.[J] .J Natl Cancer Inst, 2014, 106: undefined.

4.Choi E-B,Yang A-Y,Kim S C et al. PARP1 enhances lung adenocarcinoma metastasis by novel mechanisms independent of DNA repair.[J] .Oncogene, 2016, 35: 4569-79.

5.Schärer Orlando D,Nucleotide excision repair in eukaryotes.[J] .Cold Spring Harb Perspect Biol, 2013, 5: a012609.

6.Metro G,Zheng Z,Fabi A et al. In situ protein expression of RRM1, ERCC1, and BRCA1 in metastatic breast cancer patients treated with gemcitabine-based chemotherapy.[J] .Cancer Invest, 2010, 28: 172-80.

7.Kasimir-Bauer Sabine,Bittner Ann-Kathrin,König Lisa et al. Does primary neoadjuvant systemic therapy eradicate minimal residual disease? Analysis of disseminated and circulating tumor cells before and after therapy.[J] .Breast Cancer Res, 2016, 18: 20.

8.Abdel-Fatah Tarek M A,Ali Reem,Sadiq Maaz et al. ERCC1 Is a Predictor of Anthracycline Resistance and Taxane Sensitivity in Early Stage or Locally Advanced Breast Cancers.[J] .Cancers (Basel), 2019, 11: undefined.

9.Chen Xiaosong,Wu Jiayi,Lu Hongfen et al. Measuring $\beta$-tubulin III, Bcl-2, and ERCC1 improves pathological complete remission predictive accuracy in breast cancer.[J] .Cancer Sci, 2012, 103: 262-8.10.EL Baiomy Mohamed Ali,El Kashef Wagdi F,ERCC1 Expression in Metastatic Triple Negative Breast Cancer Patients Treated with Platinum-Based Chemotherapy[J] .Asian Pac. J. Cancer Prev., 2017, 18: 507-513.

11.Fu Jian-Min,Zhou Jie,Xie Jian-Sheng et al. [Effect of neoadjuvant chemotherapy on ERCC1 gene expression in breast cancer].[J] .Nan Fang Yi Ke Da Xue Xue Bao, 2008, 28: 603-5.

12.Ma Wang,Li Wen,Gao Ming et al. [Expression of ERCC1 mRNA and its impact on the prognosis of patients with non-small cell lung cancer].[J] .Zhonghua Zhong Liu Za Zhi, 2011, 33: 371-4.

13.Ota Shuji,Ishii Genichiro,Goto Koichi et al. Immunohistochemical expression of BCRP and ERCC1 in biopsy specimen predicts survival in advanced non-small-cell lung cancer treated with cisplatin-based chemotherapy.[J] .Lung Cancer, 2009, 64: 98-104.

14.He Lang,Wang Xiaoshan,Liu Kang et al. Integrative PDGF/PDGFR and focal adhesion pathways are downregulated in ERCC1-defective non-small cell lung cancer undergoing sodium glycididazole-sensitized cisplatin treatment.[J] .Gene, 2019, 691: 70-76. 
15.Xia Anzhou,Li Huanhuan,Li Ran et al. Co-treatment with BEZ235 enhances chemosensitivity of A549/DDP cells to cisplatin via inhibition of PI3K/Akt $/ \mathrm{mTOR}$ signaling and downregulation of ERCC1 expression.[J] .Oncol Rep, 2018, 40: 2353-2362.

16.Wang Yan,Li Jialong,Shen Cheng et al. Clinical Role of Excision Repair Cross-Complementing 1 Gene Expression in Resected Esophageal Squamous Cell Carcinoma: A Meta-Analysis.[J] .Dig Dis Sci, 2020, 65: 2264-2271.

17.Steffensen Karina Dahl,Smoter Marta,Waldstrøm Marianne et al. Resistance to first line platinum paclitaxel chemotherapy in serous epithelial ovarian cancer: the prediction value of ERCC1 and Tau expression.[J] .Int J Oncol, 2014, 44: 1736-44.

18.Hui EP, Ma BB, Chan KA, et al. Abstract 3776: Examination of ERCC1 status in circulating tumor cells as a prognostic tool for patients with nasopharyngeal carcinoma [J]. Cancer Research, 2017, 77(13): 3776-3776.

19. Yeh YS, Chen YT, Tsai HL, et al. Predictive value of ERCC1, ERCC2, and XRCC expression for patients with locally advanced or metastatic gastric cancer treated with neoadjuvant FOLFOX chemotherapy [J]. Pathol Oncol Res, 2018, 44(11): 17-22.

20.Smith Emma L,Somma Domenico,Kerrigan David et al. The regulation of sequence specific NF- $\kappa B$ DNA binding and transcription by IKK $\beta$ phosphorylation of NF- $\mathrm{KB}$ p50 at serine 80.[J] .Nucleic Acids Res, 2019, 47: 11151-11163.

21.Abdellatif Ahmed A H,Rasheed Zafar,Alhowail Ahmad H et al. Silver Citrate Nanoparticles Inhibit PMA-Induced TNF $\alpha$ Expression via Deactivation of NF- $\mathrm{kB}$ Activity in Human Cancer Cell-Lines, MCF-7.[J] .Int J Nanomedicine, 2020, 15: 8479-8493.

22.Yang Yongxin,Li Xiabin,Hao Liyue et al. The diagnostic value of DNA repair gene in breast cancer metastasis.[J] .Sci Rep, 2020, 10: 19626.

23.Huang Pei-Yu,Li Yan,Mai Hai-Qiang et al. Expression of ERCC1 predicts clinical outcome in locoregionally advanced nasopharyngeal carcinoma treated with cisplatin-based induction chemotherapy.[J] .Oral Oncol, 2012, 48: 964-968.

24. Song Lingqin,Liu Di,Zhao Yang et al. Sinomenine inhibits breast cancer cell invasion and migration by suppressing NF-kB activation mediated by IL-4/miR-324-5p/CUEDC2 axis.[J] .Biochem Biophys Res Commun, 2015, 464: 705-10.

25.Song Lingqin,Liu Di,Zhao Yang et al. Sinomenine inhibits breast cancer cell invasion and migration by suppressing NF-kB activation mediated by IL-4/miR-324-5p/CUEDC2 axis.[J] .Biochem Biophys Res Commun, 2015, 464: 705-10.

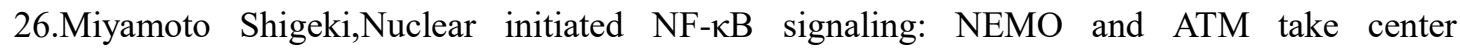
stage.[J] .Cell Res, 2011, 21: 116-30.

27.Al-Sadi Rana,Guo Shuhong,Ye Dongmei et al. TNF- $\alpha$ Modulation of Intestinal Tight Junction Permeability Is Mediated by NIK/IKK- $\alpha$ Axis Activation of the Canonical NF- $\kappa B$ Pathway.[J] .Am J Pathol, 2016, 186: 1151-65.

28.Cruceriu Daniel,Baldasici Oana,Balacescu Ovidiu et al. The dual role of tumor necrosis factor-alpha (TNF- $\alpha$ ) in breast cancer: molecular insights and therapeutic approaches.[J] .Cell Oncol (Dordr), 2020, 43: 1-18.

29.Xiao Jisheng,Duan Xiaopin,Yin Qi et al. The inhibition of metastasis and growth of breast cancer by blocking the NF- $\mathrm{KB}$ signaling pathway using bioreducible PEI-based/p65 shRNA complex nanoparticles.[J] .Biomaterials, 2013, 34: 5381-90.

30.Choi Jihye,Ahn Sung Shin,Lim Yoongho et al. Alisma canaliculatumInhibitory Effect of Ethanolic Extract on NF-kB-Dependent CXCR3 and CXCL10 Expression in TNF $\alpha$-Exposed MDA-MB-231 Breast Cancer Cells.[J] .Int J Mol Sci, 2018, 19: undefined. 


\section{Statement}

We confirming all the experiment protocol for involving humans was in accordance to guidelines of national in the manuscript. 